\title{
ANALISA PENENTUAN KEBUTUHAN DAYA MOTOR PADA MESIN PEMARUT SINGKONG
}

\author{
Soeryanto ${ }^{1}$, Agung Prijo Budijono ${ }^{2}$, Redy Ardiansyah $^{3}$ \\ 1,2,3 Jurusan Teknik Mesin, Universitas Negeri Surabaya \\ 1soeryanto@unesa.ac.id \\ 2agungbudijono@unesa.ac.id
}

\begin{abstract}
Abstrak-Singkong memiliki peranan penting sebagai bahan baku makanan pokok, bahan industri, bahan makanan ternak, maupun sebagai komoditas ekspor. Untuk komoditas ekspor biasanya singkong diolah terlebih dahulu menjadi tepung tapioka. Salah satu tahapan proses pembuatan tepung tapioka yaitu proses pemarutan singkong yang dapat dilakukan menggunakan mesin pemarut singkong. Tujuan dalam kegiatan ini yaitu menganalisa kebutuhan daya motor pada mesin pemarut singkong. Metode yang digunakan diantaranya studi literatur dan observasi di lapangan. Berdasarkan analisa data dapat diketahui bahwa daya yang diperlukan adalah $0,08 \mathrm{HP}$, jika diketahui efisien akibat transmisi sabuk sebesar $98 \%$ maka daya yang sebenarya dibutuhkan adalah $0,08 \mathrm{HP}: 98 \%=0.082 \mathrm{HP}$. Jika dipilih motor dengan daya 0,25 HP, dengan efisiensi motor dengan beban penuh sebesar $66 \%$ maka daya motor yang sebenarnya adalah $0,25 \mathrm{HP}><66 \%=$ 0,165 HP. Dari perhitungan tersebut maka motor dengan daya 0,25 HP dapat digunakan untuk menggerakkan mekanisme pemarut.
\end{abstract}

Kata Kunci-Analisa daya; motor; mesin pemarut; singkong.

\begin{abstract}
Cassava has an important role as raw material for staple foods, industrial materials, animal feed ingredients, and as an export commodity. For export commodities cassava is usually processed first into tapioca flour. One of the stages of making tapioca flour is the process of coating cassava which can be done using a cassava grater machine. The purpose of this activity is to analyze motor power requirements in the cassava grater machine. The methods used include literature studies and field observations. Based on data analysis, it can be seen that the power needed is $0.08 \mathrm{HP}$, if it is known to be efficient due to belt transmission of $98 \%$, the actual power needed is $0.08 \mathrm{HP}: 98 \%=0.082 \mathrm{HP}$. If you select a motor with a power of $0.25 \mathrm{HP}$, with the efficiency of a motor with a full load of $66 \%$, the actual motor power is $0.25 \mathrm{HP}><66 \%=0.165 \mathrm{HP}$. From these calculations the motor with a power of $0.25 \mathrm{HP}$ can be used to drive the grater mechanism.
\end{abstract}

Keywords - Power analysis; motor; grater machine; cassava.

\section{Pendahuluan}

Sebagai tanaman sumber karbohidrat, singkong memiliki peranan penting sebagai bahan baku makanan pokok, bahan industri, bahan makanan ternak, maupun sebagai komoditas ekspor. Untuk komoditas ekspor biasanya singkong diolah terlebih dahulu menjadi tepung tapioka. Sebagai bahan industri singkong dapat dijumpai dalam dalam bentuk gula singkong. Selain itu tepung atau ampas tapioka dibuat sebagai perekat hardboard atau industri kimia. Sebagai pakan ternak biasanya tepung singkong digunakan sebagai campuran bahan pakan unggas.

Sebelum dijadikan tepung tapioka singkong diolah dulu dengan cara diparut baru kemudian diperas untuk mendapatkan pati. Pemarutan singkong bisa dilakukan dengan cara yaitu pemarutan dengan cara manual dan mekanis. Pemerasan juga dapat dilakukan dengan dua cara yaitu pemerasan bubur singkong dengan menggunakan kain saring kemudian diremas-remas atau dengan saringan goyang dimana bubur singkong diletakkan di atas saringan yang digerakkan dengan mesin, sementara saringan tersebut bergoyang, pati yang dihasilkan ditampung dalam bak pengendapan. Kedua proses ini dilakukan dengan menggunakan dua alat yang terpisah, sebagai konsekuensinya memerlukan waktu untuk memindah produk dari mesin ke mesin yang lain sehingga dalam pelaksanaanya kurang efisien.

Berbagai masalah di atas perlu dicari solusinya melalui ilmu dan teknologi, salah satunya dalam hal tenaga penggerak pada suatu alat mesin. Penggunaan tenaga penggerak yang dari semula menggunakan tenaga manusia atau binatang dirasakan kurang efisien, maka digantilah tenaga penggerak yang lebih praktis dan dituntut ekonomis yaitu dengan menggunakan tenaga mesin. Dari pergantian ini diharapkan hasil yang diperoleh lebih baik dalam hal kualitas dan kuantitasnya, apabila kedua aspek telah terpenuhi maka produksi serta pendapatan akan meningkat.

Untuk itu maka diperlukan suatu mesin pemarut singkong yang lebih baik dan lebih efisien dari sebelumnya. Dalam perancangan mesin perlu dianalisa terlebih dahulu tentang spesifikasi komponen yang dibutuhkan agar mesin dapat berfungsi dengan maksimal. Dalam artikel ini hanya membahas tentang analisa kebutuhan daya mekanik dari mesin pemarut singkong.

Alat pembuat tepung tapioka ini terdiri dari bagian rangka, hopper, silinder pemarut, poros penggilas, plat penyaring, komponen transmisi, serta bak penampung. 
Mekanisme pemarutan dilakukan oleh silinder pemarut, silinder pemarut berfungsi untuk menghancurkan singkong yang berukuran besar menjadi beberapa fraksi dengan ukuran yang lebih kecil. Sedangkan untuk mekanisme pada penggilas dilakukan oleh poros penggilas yang berfungsi untuk menggilas singkong yang telah diparut sehingga sari pati yang terdapat pada singkong dapat keluar secara maksimal. Untuk menghitung komponen komponen pada alat pembuat tepung tapioka diatas maka digunakan teori-teori sebagai berikut :

\section{A. Torsi, Daya, dan Putaran}

Dalam sistem satuan yang lazim di AS, daya dinyatakan dalam horsepower, yang sama dengan 550 $\mathrm{ft} . \mathrm{lb} / \mathrm{s}$. Satuan untuk putaran adalah rpm (revolution per minute) atau putaran per menit. Tetapi satuan yang sangat tepat untuk torsi adalah pon.in (lb.in). Dengan menganggap semua besaran ini dan dengan membuat konversi satuan yang diperlukan, digunakan rumus berikut ini untuk menghitung torsi dalam sebuah poros yang membawa daya $\mathrm{P}$ (dalam hp) yang berputar dengan kecepatan $\mathrm{n}$ rpm. [1]

$T=(63000 \mathrm{P} / \mathrm{n})$

dimana :

$P \quad=$ daya motor yang dibutuhkan (hp)

$T \quad=$ torsi (kg.m)

$n \quad=\operatorname{putaran}(\mathrm{rpm})$

\section{B. Torsi Inersia}

Gaya Iuar yang bekerja pada benda dengan kondisi dimana suatu benda simetris jika berputar pada suatu sumbu yang tetap tegak lurus dengan luasan bidang dan melalui pusat massa $\mathrm{G}$ sama dengan kopel $l \alpha$. Kopel ini disebut torsi inersia, yang merupakan akibat dari adanya momen inersia massa benda tersebut dan adanya percepatan sudut sesaat sebelum benda tersebut berputar hingga mencapai putaran konstan. [2]

Dalam mencari torsi inersia terlebih dahulu harus dicari momen inersia massa untuk berbagai bentuk benda yang umum. Torsi inersia dapat dicari dengan menggunakan persamaan berikut :

$$
T=I \cdot \alpha
$$

dimana :

$\mathrm{T}=$ torsi pemarut $(\mathrm{Nm})$

$I \quad=$ momen inersia massa total $\left(\mathrm{kg} \cdot \mathrm{m}^{2}\right)$

$\alpha=$ percepatan sudut pemarut $\left(\mathrm{rad} / \mathrm{s}^{2}\right)$

\section{Pegas}

Pegas dapat dikelompokkan sesuai dengan arah dan sifat gaya yang dihasilkan ketika pegas mengalami defleksi. Tabel 1 mendaftar beberapa kelompok pegas seperti tekan, tarik, radial dan puntir. Gambar 1 menunjukkan beberapa konfigurasi jenis rancangan pegas. Pegas ulir tekan, umumnya terbuat dari kawat bundar, dililitkan lurus, berbentuk silindris dengan jarak bagi konstan antara lilitan satu dengan lilian selanjutnya. Pegas ulir tarik, kelihatan mirip dengan pegas ulir tekan, tetapi pada pegas ulir tarik jarak antar lilitan lebih dekat dan bersinggungan ketika pegas tidak terbebani. Gambar 2 menunjukkan beberapa konfigurasi ujung dari pegas tekan.
Pegas rajutan (drawbar spring) menggabungkan pegas ulir standar dengan dua kawat yang dikaitkan dalam lilitan pegas. Dengan rancangan seperti itu, gaya tarik dapat dihasilkan dengan cara menarik kawat pengait sementara pegas dalam keadaan tertekan. Pegas puntir (torsion spring), sesuai dengan namanya digunakan untuk mengahasilkan torsi selama pegas terdefleksi oleh putaran sumbunya. Pada umumnya pegas jepitan baju menggunakan pegas puntir untuk mengahasilkan penjepitan. Pegas daun (leaf spring), terbuat dari bilahbilah datar kuningan, perunggu atau baja atau bahab lain yang dibebani batang kantilever atau balok sederhana.

Tabel 1. Jenis-jenis pegas

\begin{tabular}{|l|l|}
\hline Penggunaan & Jenis-jenis pegas \\
\hline Tekan & $\begin{array}{l}\text { Pegas ulir tekan, Pegas piring, Pegas } \\
\text { puntir; gaya beraksi pada ujung lengan } \\
\text { punter, Pegas rata; semisal kantilever atau } \\
\text { pegas daun }\end{array}$ \\
\hline Tarik & $\begin{array}{l}\text { Pegas ulir tarik, Pegas puntir; gaya beraksi } \\
\text { pada ujung lengan punter, Pegas rata; } \\
\text { semisal kantilever atau pegas daun. Pegas } \\
\text { rajutan (aplikasi khusus pegas tekan), } \\
\text { Pegas gaya konstan }\end{array}$ \\
\hline Radial & $\begin{array}{l}\text { Pegas kumparan cincin,pita elastomeric, } \\
\text { pegas jepit }\end{array}$ \\
\hline Torsi & Pegas puntir, pegas gaya \\
\hline
\end{tabular}

[2]

Pegas piring (belleville spring), mempunyai bentuk cekungan dangkal atau cakram konis dengan lubang di tengahnya. Kadang kadang disebut cincin Belleville karena menyerupai cincin rata. Pegas kumparan cincin (garter spring), adalh lilitan kawat yang dibentuk menjadi sebuah cincin sehingga menghasilkan gaya radial disekeliling objek dimana pegas ini digunakan. [3]

Pegas gaya konstan (constan-force spring) berbentuk gulungan bilah pelat. Gaya yang diperlukan untuk menarik pelat keluar dari gulungan memeng konstan sepanjang tarikannya. Pegas daya (power spring), kadang disebut pegas motor atau pegas jam. Terbuat dari baja pegas rata, digulung menjadi bentuk spiral.Tordi yang dihasilkan oleh pegas mengingat pegas cenderung terbuka dari gulungannya. Batang puntir (torsion bar), sesuai namanya merupakan batang yang dibebani puntiran. [3]

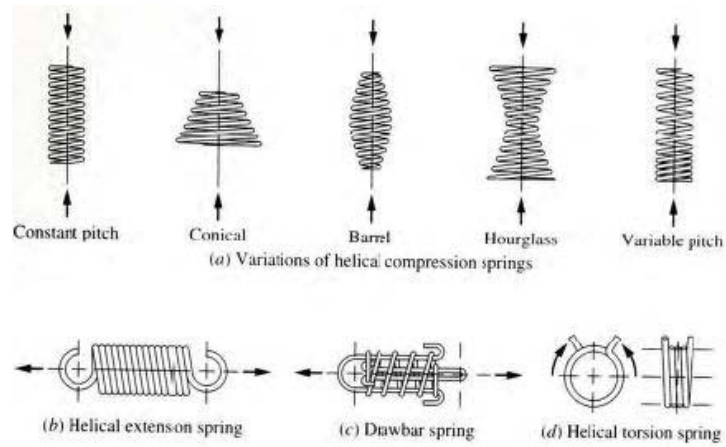


Gbr 1. Jenis-jenis pegas. [2]

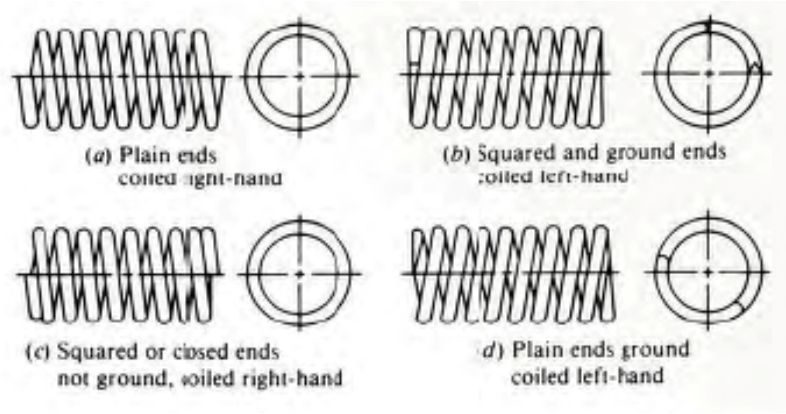

Gbr 2. Tampilan pegas ulir tekan dengan perlakuan pada ujungnya.

\section{METODE}

Langkah-langkah yang akan dilakukan dalam menganalisa kebutuhan daya mekanik mesin pemarut singkong adalah sebagai berikut :

- Studi literatur untuk mencari data-data yang berhubungan dengan topik serta mencari rumus-rumus yang menunjang perhitungan ini.

- Mencari buku yang diperlukan dalam proses pemesinan disertai pemilihan elemen yang direncanakan.

- Mempelajari mekanisme yang akan dibuat meliputi hasil yang diinginkan dan elemen mesin yang digunakan.

- Membuat mekanisme yang terfokus pada permasalahan yang dibahas.

- Menganalisa kebutuhan daya mekanik mesin

- Membuat kesimpulan.

- Menyusun laporan.

\section{HASIL DAN DISKUSI}

\section{A. Mekanisme Pemarut Singkong}

Pemarutan singkong adalah suatu proses untuk memecahkan dinding sel pada umbi singkong agar butir pati yang terdapat di dalamnya dapat keluar. Untuk mendapatkan hasil yang maksimal maka diperlukan suatu alat yang dapat memenuhi permintaan diatas. Jika pemarutan tersebut dilakukan secara manual. Maka akan memakan waktu yang cukup lama dan tenaga manusia yang cukup besar.

Penghancuran atau pelumatan singkong dapat dilakukan dengan berbagai cara. diantaranya adalah :

1. Menggunakan parut berputar. Pada proses pemarutan ini singkong yang telah dikupas dan dicuci digilas dengan menggunakan silinder yang mendesak pada celah dengan besar tertentu. silinder digerakkan dengan diputar menggunakan motor. Proses ini dilakukan dengan sebuah silinder pemarut yang berotasi dan penggilasan terjadi akibat gaya radial silinder.

2. Menggunakan pemarut manual/tetap. Pada proses pemarutan ini digunakan suatu plat tipis terbuat dari aluminium, plat besi, atau parut yang beralas papan. Jenis parut yang beralas papan, gigi parutnya dibuat dari baja yang ditancapkan pada jarak tertentu. Untuk parut yang terbuat dari alumiunium atau plat besi gigi parutnya dibuat dari bahan itu sendiri dengan cara dicongkel sehingga lembaran tersebut menjadi kasar dan berbentuk seperti paku-paku tajam. Permukaan yang kasar dan tajam ini akan menyayat singkong sehingga menjadi butiran butiran yang lebih lembut.

Dari kedua mekanisme di atas dapat dipertimbangkan mekanisme yang akan dipilih :

- Pada pemarutan dengan menggunakan silinder berparut yang berputar dilihat dari segi pruduktivitas maka mekanisme ini mempunyai prokdutivitas yang cukup tinggi.

- $\quad$ Pada pemarutan secara manual tidak cukup efektif karena memerlukan tenaga manusia yang cukup banyak. dan memerlukan waktu yang lama.

Dari kedua poin diatas maka dapat disimpulkan mekanisme yang akan digunakan adalah mekanisme pemarut dengan menggunakan pemarut silinder berputar. Cara ini cukup efektif karena proses pemarutan dapat dilakukan secara kontinyu karena selama silinder pemarut berputar singkong dapat diparut.

Untuk mekanisme pemarut ini. digunakan penggerak berupa motor yang akan menggerakkan puli maka mekanisme pemarut akan memiliki kecepatan yang konstan dan motor yang akan menggerakkan puli silinder pemarut dengan menggunakan v-belt. Dengan berputamya puli pemarut tersebut, maka singkong yang telah dikupas dan dicuci yang ada pada wadah digilas dengan silinder berparut yang mendesak pada celah dengan besar tertentu. Hasil parutan akan keluar melalui plat penampung hasil parutan.

\section{Perhitungan Mekanisme Pemarut}

Dalam membuat mesin pembuat tepung tapioka ini ada bagian-bagian dari mesin yang harus direncanakan atau dihitung secara teoritis, yaitu :

1. Motor Listrik

2. Poros

3. Pasak

4. Puli

5. Bantalan

6. Sproket

Mesin pembuat tepung tapioka ini direncanakan menggunakan motor dengan putaran sebesar $\left\{400 \mathrm{rpm}\left(\mathrm{n}_{1}\right)\right.$. Untuk menyesuaikan antara putaran yang dibutuhkan dengan putaran yang tersedia, sekaligus sebagai transmisi daya digunakan sistem puli. Puli yang digunakan adalah puli yang berbentuk standar yang banyak terdapat dipasaran dan diameter puli pada motor ditentukan 2 inch. Jadi kecepatan putar dari mesin pemarut dapat dicari dengan menggunakan rumus [4]:

$$
\frac{d_{y w d 2}}{d_{y u l 1}}=\frac{n_{1}}{n_{2}}
$$

dimana :

$\mathrm{d}_{\text {puli }}=$ diameter puli motor listrik (inch)

$\mathrm{d}_{\text {puli2 }}=$ diameter puli pemarut [inch) 
$\mathrm{n}_{1} \quad=$ putaran motor listrik (rpm)

$\mathrm{n}_{2} \quad=$ putaran pemarut $(\mathrm{rpm})$

$$
\begin{aligned}
& \frac{4,5}{2}-\frac{1400}{r_{2}} \\
& \mathrm{n}_{2}=622 \mathrm{rpm}
\end{aligned}
$$

\section{B. Perhitungan Daya mekanisme Pemarut}

Untuk menentukan daya yang dibutuhkan pada waktu proses pemarutan singkong ini, perlu dicari torsi dari mekanisme dalam keadaan tanpa beban dan dalam keadaan terbebani. Dalam perhitungan torsi dari mekanisme dalam keadaan tanpa beban, diperlukan perhitungan momen inersia pada mekanisme pemarut ini.

1. Perhitungan Momen Inersia Massa Silinder Pemarut

Silinder pemarut pada mekanisme ini berfungsi untuk memecahkan dinding sel pada umbi singkong agar butir pati yang terdapat di dalamnya dapat keluar. Untuk perencanaan lebih lanjut diperlukan data-data sebagai berikut :

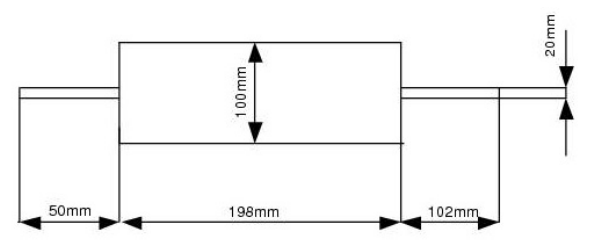

Gbr 2. Tabung Parut

- berat dari pemarut $\quad=1,9 \mathrm{KG}$

- inersia massa dari silinder pemarut dapat dihitung dengan rumus [3] :

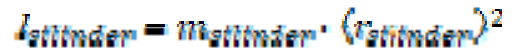

- untuk mengetahui massa dari silinder pemarut maka dicari terlebih dahulu massa dari poros pemarut :

$\mathrm{m}_{\text {pemarut }}=\mathrm{m}_{\text {silinder }}+\mathrm{m}_{\text {poros }}$

dimana : massa poros pemarut dapat dicari dengan rumus sebagai berikut [1]:

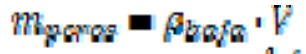

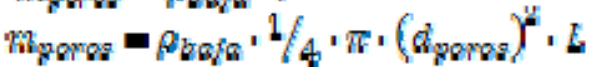

$$
\begin{aligned}
& m_{\text {ger }}-7,88,10^{2}, 1 / 4, \pi \cdot(0,22)^{2}, 0,35 \\
& \text { mingrag } 0,86 \mathrm{~kg}
\end{aligned}
$$

Jadi massa silinder pemarut adalah :

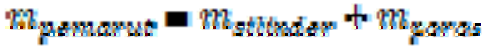

$$
\begin{aligned}
& 1,9 \mathrm{~kg}=\mathrm{m}_{\mathrm{ghin}} \mathrm{men}+0,86 \mathrm{~kg} \\
& \text { migtiondem }=1,04 k 8
\end{aligned}
$$

Jadi momen inersia massa dari silinder pemarut ada lah [1]:

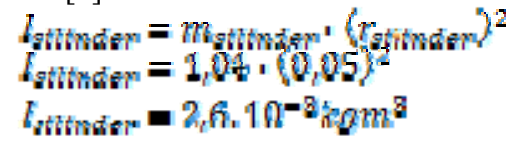

\section{Perhitungan Momen Inersia Massa Poros Pemarut}

Poros pada mekanisme ini berfungsi untuk mentransmisikan daya yang berasal dari motor untuk menjalankan proses pemarutan. Untuk perencanaan lebih lanjut diperlukan data-data sebagai berikut [1]:

$$
\begin{array}{ll}
\text { - } \quad \rho_{\text {baja }} & =7,83 \cdot 10^{3} \mathrm{~kg} / \mathrm{m}^{3} \\
\text { - } \quad \text { panjang poros } & =35 \mathrm{~cm}=0,35 \mathrm{~m} \\
\text { - } \quad \mathrm{d}_{\text {poros }} & =2 \mathrm{~cm}=2.10^{-3} \mathrm{~m}
\end{array}
$$

massa poros dapat dihitung dengan rumus :

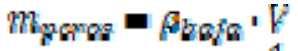

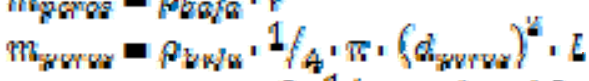

$$
\begin{aligned}
& m_{\text {FW }}=7,88.20^{2} \cdot 1 / 4 \cdot \pi \cdot(0,02)^{2} \cdot 0,35 \\
& \text { migomge }-0,86 k g
\end{aligned}
$$

Inersia massa poros dapat dihitung dengan rumus :

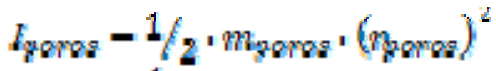

$$
\begin{aligned}
& l_{\text {poras }}=1 / 2 \cdot 0,06 \cdot(0,01)^{2} \\
& I_{\text {prma }}-4,3,10^{-5} \mathrm{kgm}^{2}
\end{aligned}
$$

\section{Perhitungan Momen Inersia Massa Puli Pemarut}

Puli yang dipakai pada mekanisme pemarut ini terbuat dari besi dengan massa jenis sebesar $\left(\rho_{\text {besi }}\right)=7870 \mathrm{~kg} / \mathrm{m}^{3}$, sedangkan diameter dari puli sebesar $\left(\mathrm{d}_{\text {puli }}\right)=11,43 \mathrm{~cm}=$ $0,1143 \mathrm{~m}$ dan memiliki tebal sebesar $\left(\mathrm{L}_{\text {puli }}\right)=2 \mathrm{~cm}=0,02$ $\mathrm{m}$. Sehingga massa dari puli dapat dihitung dengan rumus $[2$ :

$$
\begin{aligned}
& m_{\text {guth }} \cdot P_{\text {begt }} \cdot V
\end{aligned}
$$

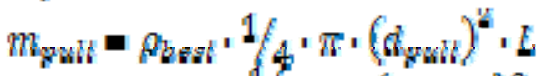

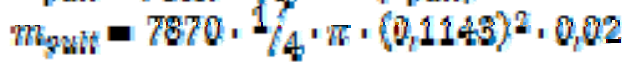

$$
\begin{aligned}
& m_{\text {puli }}=1,61 \mathrm{~kg}
\end{aligned}
$$

Inersia massa puli dapat dihitung dengan rumus :

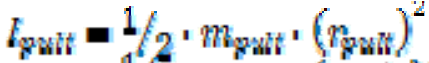

$$
\begin{aligned}
& f_{\text {gut }}=1 / 2 \cdot m_{\text {rut }} \cdot(0,057)^{2} \\
& Z_{\text {gun }}-2,62,10^{-5} \mathrm{kgm}^{3}
\end{aligned}
$$

Jadi momen inersia total adalah :

$$
\begin{aligned}
& E_{\text {total }}=E_{\text {stitnden }} \mid E_{\text {gtzhnaen }} \text { I } E_{\text {puti }} \\
& I_{\text {total }}=2,6,10^{-2}+4,3,10^{-3}+2,62,10^{-8} \\
& l_{\text {total }}=5,26,10^{-3} \mathrm{kgm}^{2}
\end{aligned}
$$

4. Perhitungan Torsi Pemarut

- menghitung kecepatan sudut dapat dicari dengan menggunakan rumus [1] :

$$
\omega_{\text {grmaras }}=\frac{2 \cdot \pi \cdot n}{\sigma 0} r \alpha \delta_{s}
$$




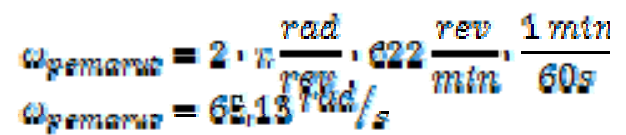

- menghitung percepatan sudut dapat dicari dengan menggunakan rumus [1]:

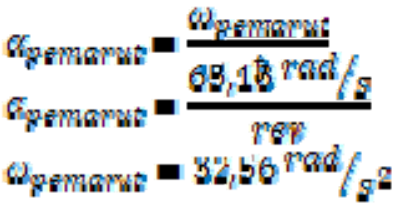

waktu (t), didapatkan dari percobaan menggunakam tachometer dan stopwatch yang kegunaannya sebagai pengukur kecepatan hingga diperoleh kecepatan konstan.

Jadi torsi pemarut dapat dihitung dengan rumus [1]:

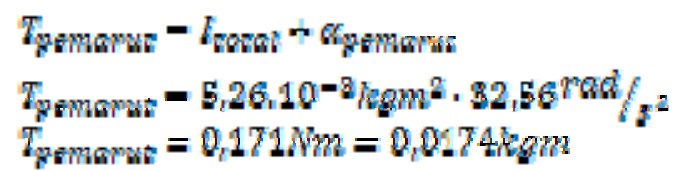

Torsi ini terjadi pada saat mesin pengupas belum terbebani. Untuk mengetahui torsi yang terbebani pada saat mesin terbebani adalah dengan melakukan percobaan-Percoabaan yang dilakukan adalah dengan memasang lengan bandul yang memiliki massa tertentu yang dipengaruhi gaya gravitasi, akibatnya pemarut akan berputar dan diberi masa $(\mathrm{kg})$ sampai singkong terparut.

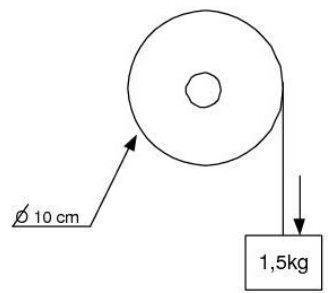

Gbr 3. Model Pengujian Torsi

Dari percobaan tersebut diperoleh massa (n1) sebesar I,5 kg yang dapat mengakibatkan pemarut berputar dan singkong terparut. Sehingga torsi yang terjadi saat mesin terbebani adalah [4]:

$$
\begin{aligned}
& F=m \cdot g \\
& F=1,5: g \cdot 9,81 \mathrm{~m} / \mathrm{s}^{2} \\
& F=14,7 \mathrm{~N}
\end{aligned}
$$

$$
\begin{aligned}
& T=F
\end{aligned}
$$

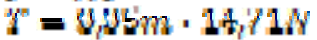

$$
\begin{aligned}
& T=0,7355 N m \\
& T=\frac{0,7555}{9,81} \\
& T=0,075 \mathrm{~kg} \cdot m
\end{aligned}
$$

Torsi ini terjadi saat mesin terbebani.

Jadi torsi total dari mesin pemarut adalah :

$$
T_{\text {total }}=0,0174 \mathrm{~kg} \cdot \mathrm{m}+0,075 \mathrm{~kg} \cdot \mathrm{m}
$$

$$
T_{\text {total }}=0,0924 \mathrm{~kg} \cdot \mathrm{m}
$$

Maka daya motor yang dibutuhkan dapat dihitung dengan rumus [2]:

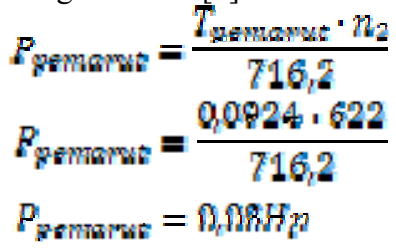

\section{KESIMPULAN}

Berdasarkan hasil analisa data yang teah dilakukan, maka dapat disimpulkan bahwa kebutuhan daya yang diperlukan untuk mesin pemarut singkong meadalah $0,08 \mathrm{Hp}$, Jika diketahui efisien akibat transmisi sabuk sebesar $98 \%$ maka daya yang sebenarya dibutuhkan adalah $0,08 \mathrm{HP}: 98 \%$ $=0.082 \mathrm{HP}$. Jika dipilih motor dengan daya $0,25 \mathrm{HP}$, dengan efisiensi motor dengan beban penuh sebesar $66 \%$ seperti yang tercantum pada tabel motor, maka daya motor yang sebenarnya adalah $0,25 \mathrm{HP}>66 \%=0,165 \mathrm{HP}$. Dari perhitungan tersebut maka motor dengan daya $0,25 \mathrm{HP}$ dapat digunakan untuk menggerakkan mekanisme mesin pemarut singkong.

\section{REFERENSI}

[1] L. Mott, Robert. 2004. Machine Elements in Mechanical Design. New Jersey: Pearson Education.

[2] L. Mott, Robert. 2009. Elemen-Elemen Mesin dalam Perancangan Mekanis. Yogyakarta: ANDI.

[3] Sato, G. Takeshi dan Sugiarto, N. 1999. Menggambar Mesin. Jakarta: PT. Pradnya Paramita.

[4] Sularso dan Suga, Kiyokatsu. 2004. Dasar Perencanaan dan Pemilihan Elemen Mesin. Jakarta: PT. Pradnya Paramita. 